\title{
Ecological features and new location of the rare relict species Craniospermum pseudotuvinicum (Boraginaceae)
}

\author{
Svetlana Ovchinnikova* \\ Central Siberian Botanical Garden, SB RAS, 630090, Novosibirsk, Zolotodolinskaya str. 101, Russia
}

\begin{abstract}
Information on the new location of the high-mountainous species Craniospermum pseudotuvinicum (endemic to Mongolia) is given. The morphological and ecological-cenotic features of the species, as well as known locations within the Central Mongolian-Altai province are considered.
\end{abstract}

When performing a critical revision of taxa of the family Boraginaceae Juss. on the territory of Outer Mongolia and the study of the extensive herbarium collections of the Central Asia Department of the Herbarium of the Botanical Institute V. L. Komarova of the Russian Academy of Sciences (LE), we found a specimen (not previously defined), which we assigned to the recently described species Craniospermum pseudotuvinicum Ovczinnikova et A. Korolyuk: "Outer Mongolia, the Great Lakes Basin, m. Batar Khairkhan (eastern part), alt. $2500 \mathrm{~m}$ above sea level, southern exposition, on scree, sedge-petrophyte-forb community, 26 VII 1983, N 255, E.A. Volkova, I.Yu. Sumerina, U. Beckett, H. BuyanOrshy"(LE).

The found plants are perennial stem-root with many-headed caudex loose frutescentes monopodially growing polycarpic with a main vegetative rosette shoot and elongated axillary generative shoots. Rosette leaves are back-lanceolate, rounded at the top, 8-12 cm long., $1.0-2.0 \mathrm{~cm}$ wide, densely pubescent with thin long, $2-2.5 \mathrm{~mm}$, half-adherent gray hairs and short soft hairs. Flowering stems are $10 \mathrm{~cm}$ tall, simple, distant hairy, leafy to the inflorescence. Inflorescence is a double coil, almost capitate, $3.3 \mathrm{~cm}$ long. Calyx is mildly tangled-white-haired with back-lanceolate lobes, 7.0-8.5 mm long. Corolla is lilac, saffron when dry, 9.0-10.0 mm long, dolichomorphic. Corolla teeth are $1.3 \mathrm{~mm}$ long. Anthers are 1.1-1.2 mm long., slightly exposed from the corolla. The stigma is hidden inside the corolla. The plant is flowering, the fruits are not known.

The analysis showed that the characteristics of the life form, the pubescence of the leaves and calyx, the signs of the inflorescence and the flower, the size of the anthers, and the ecological features of the plants correspond to the characteristics of $\mathrm{C}$. pseudotuvinicum.

Species of the genus Craniospermum Lehm. are perennial dense-custy grasses, common in semi-desert-steppe belt of Central Kazakhstan, southern Siberia, Mongolia, and Northern China, from $42^{\circ}$ to $55^{\circ} \mathrm{N}$. As shown by palynomorphological studies, the genus

*Corresponding author: sv-ovchin@yandex.ru 
Craniospermum can be attributed to the earliest representatives of the ancient Mediterranean flora [1]. Currently, the genus includes 8 species that are part of 3 sections: C. subvillosum Lehm. (section Craniospermum) is an endemic of the littoral of Lake Baikal within the Irkutsk Region and the Republic of Buryatia; C. canescens DC. and C. desertorum Ovczinnikova et A. Korolyuk (section Leucolachnos Ovczinnikova) are endemics of the Russian and Mongolian Altai; C. subfloccosum Krylov (subsection Floccosa Ovczinnikova of the section Diploloma (Schrenk) Popov) is a narrow endemic of the Russian (Katunsky Ridge) and the Kazakhstan Altai (Narymsky Ridge); C. echioides (Schrenk) Bunge (section Diploloma) is an endemic of Dzungaria within the three states of Kazakhstan, Mongolia and China; C. mongolicum I.M. Johnston (section Diploloma) is endemic to Mongolia and China within northern Xinjiang and Inner Mongolia; C. tuvinicum Ovczinnikova (section Diploloma) is endemic to Tyva and Mongolian Altai; C. pseudotuvinicum Ovczinnikova et A. Korolyuk (section Diploloma) is a narrow endemic of the Mongolian Altai. All species of the genus Craniospermum are found on dry gravelly slopes and scree, in the crevices of rocks in the belt of high-altitude and upland-xerophyte steppes, in their ecological confinement cryoxerophytes [2-5].

The species C. pseudotuvinicum was described from the eastern foothills of the Zhargalant-Khairkhan-Ula massif within the Chandman somon of the Khobdos aimag (holotype - NSK0000710). The classical location and newly discovered one are located in the Great Lakes Basin region (Fig. 1). Locations are indicated on a map made with SimpleMappr (http://www.simplemappr.net).

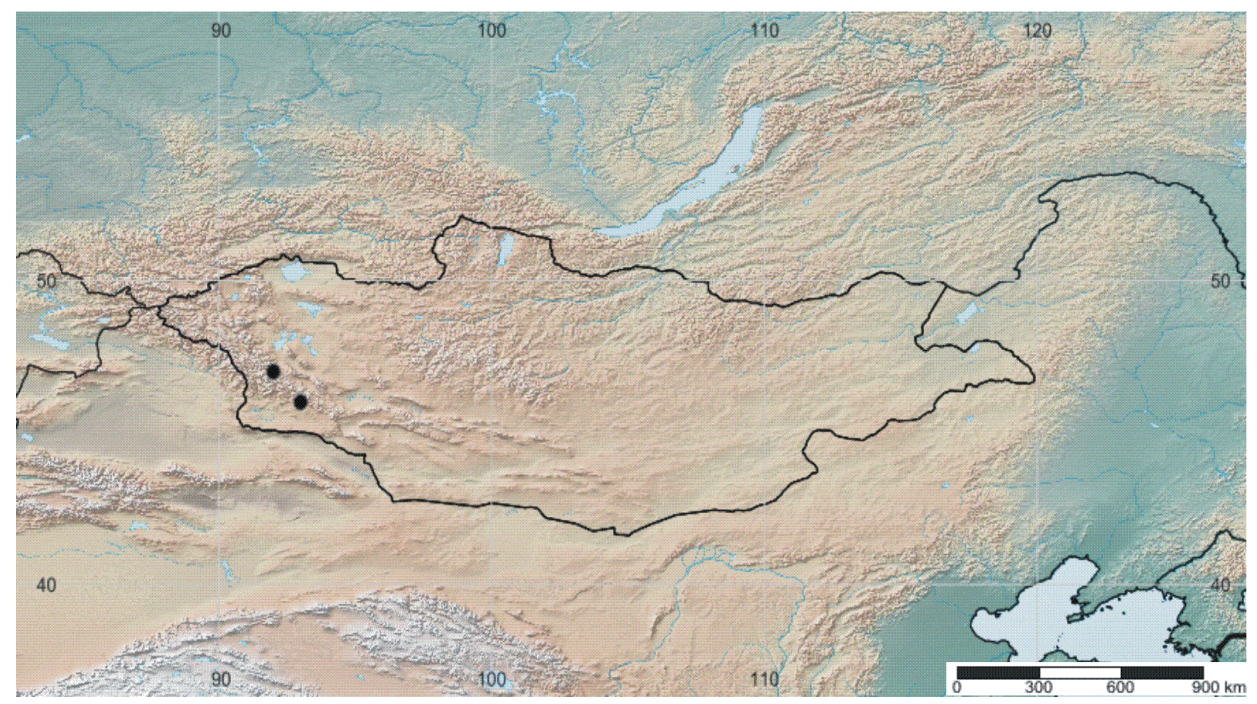

Fig. 1. Map of the areal of Craniospermum pseudotuvinicum.

The eastern part of the Batar-Khairkhan Ridge and the eastern foot of the town of Zhargalant-Khairkhan-Ula are located at an altitude of 2400-2550 m above sea level within the Central Mongolian-Altai province in the region dominated by dry sod-grassland steppes, the usual dominants of which are widespread steppe species: Poa attenuata Trin., Koeleria cristata (L.) Pers, Stipa krylovii Roshev. Habitats are mainly sloping with poorly developed stony soils with high activity of petrophytic species: Festuca lenensis Drobov, Eremogone meyerii (Fenzl) Ikonn., Amblynotus rupestris (Pall. Ex Georgi) Popov ex Seg., Orostachys spinosa (L.) C.A. Mey. At heights of $2600 \mathrm{~m}$ and more the grass-sedge cryophytic steppes begin to play an important role in vegetation cover. These communities are characterized by high abundance of Festuca kryloviana Reverd., Poa attenuata Trin., Carex rupestris All., Oxytropis oligantha Bunge, Potentilla nivea L. and Eremogone 
meyerii (Fenzl) Ikonn. Due to the considerable dissection of the relief, unclosed groups of petrophytic plants are widespread at all heights, among which Craniospermum pseudotuvinicum.

The main types of communities of the Central Mongolian-Altai province are characteristic of Mongolia or Central Asia as a whole, but a rather large number of communities are endemic Mongol-Altai or even Central-Mongol-Altai types [5, 6].

The work was performed as part of the state assignment of the Central Siberian Botanical Garden of the Siberian Branch of the Russian Academy of Sciences on the project AAAA-A17-117012610055-3 "Biological diversity of cryptogamic organisms (algae, fungi, lichens) and vascular plants in the geospace of biotic and abiotic factors, their role in aquatic and terrestrial ecosystems of North Asia". In preparing the publication, materials of the bioresource scientific collection of CSBG SB RAS "Herbarium of Higher Vascular Plants, Lichens and Fungi (NS, NSK)”, UNU № USU 440537 were used.

\section{References}

1. S.V. Ovchinnikova, Bot. Journ., 86, 12 (2001)

2. S.V. Ovchinnikova, Bot. Journ., 85, 12 (2000)

3. S.V. Ovchinnikova, Turczaninowia, 22 (to be published)

4. S.V. Ovchinnikova, V.P. Orlov, Bot. Journ., 90, 9 (2005)

5. S.V. Ovchinnikova, A.Yu. Korolyuk, Plant Life of Asian Russia, 3(23) (2016)

6. E.A. Volkova, Botanical geography of Mongolian and Gobian Altai (Komarov Botanical Institute, St. Petersburg, 1994) 